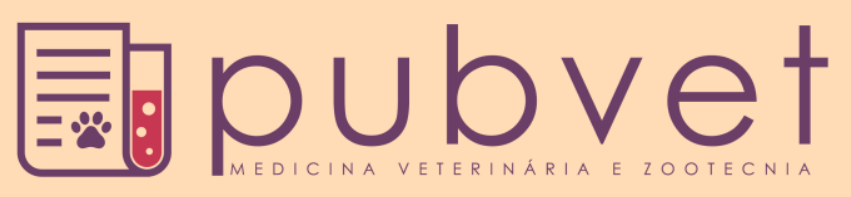

https://doi.org/10.31533/pubvet.v12n11a212.1-8

\title{
Silagem da palma forrageira consorciada com resíduos da mandioca e bagaço da cana de açúcar: Revisão
}

\author{
Maria Alves dos Santos ${ }^{1 *}$, Betina Raquel Cunha dos Santos ${ }^{20}$ \\ ${ }^{I}$ Graduanda em Engenharia Agronômica da Universidade Federal do Acre, Departamento de Forragicultura, Rio Branco - Acre Brasil. \\ ${ }^{2}$ Pesquisadora Bolsista PNPD/CAPES da Universidade Federal do Acre, Rio Branco-Acre, Brasil. E-mail: cunhabrs@yahoo.com.br \\ *Autora para correspondência, E-mail: arthamaria@hotmail.com.
}

RESUMO. Um dos grandes desafios da produção animal no Brasil é buscar alternativas alimentares disponíveis de acordo com as características regionais, eficientes, de baixo custo, que atendam às necessidades dos animais e sejam ambientalmente corretas. Nesse sentido, é importante que se avaliem a qualidade de restos culturais e de resíduos agroindustriais que apresentem potencial para uso na alimentação de ruminantes, e que também possam ser disponibilizados no período de escassez de alimentos, onde é necessária a suplementação animal para viabilidade dos sistemas produtivos. Objetiva-se nesta revisão compilar informações para a formulação de uma silagem a base da palma forrageira consorciada com os resíduos da mandioca e bagaço da cana de açúcar, de alto valor nutritivo e que não cause problemas digestivos para os animais. Serão estudados $\mathrm{pH}$, matéria seca (MS), matéria mineral $(\mathrm{MM})$, proteína bruta $(\mathrm{PB})$, extrato etéreo (EE), fibra em detergente neutro (FDN), fibra em detergente ácido (FDA), análise sensorial da silagem e de perdas gasosas. A partir do presente estudo, pretende-se gerar e disponibilizar informações e alternativas referentes a forragens conservadas na forma de silagem e, consequentemente, contribuir para o incremento da rentabilidade de diversos segmentos da cadeia produtiva de bovinos e ovinos em pastejo.

Palavras chave: composição química-bromatológica, conservação de forragem

\section{Palm silage forage with the cassava and sugarcane bagasse by-products: Review}

\begin{abstract}
One of the great challenges of animal production in Brazil is to find food alternatives available according to regional characteristics, efficient, low cost, meet the needs of animals and are environmentally correct. In this sense, it is important to evaluate the quality of cultural residues and agroindustrial residues that have potential for use in ruminant feeding, and that can also be made available in the period of food shortages, where animal supplementation is necessary for systems viability productive. The objective of this review is to compile information to formulate a silage based on forage palm intercropped with the cassava and sugarcane bagasse residues, which are high in nutritional value and do not cause digestive problems for animals. PH, dry matter (DM), mineral matter (MM), crude protein $(\mathrm{CP})$, ethereal extract (EE), neutral detergent fiber (NDF), acid detergent fiber (FDA), silage sensory analysis and of gaseous losses. From the present study, we intend to generate and make available information and alternatives regarding forages kept in the form of silage and, consequently, to contribute to the increase of the profitability of several segments of the productive chain of grazing cattle and sheep.
\end{abstract}

Keywords: chemical-bromatological composition, forage conservation 


\section{Ensilaje de palma doce consorciada con residuos de yuca y bagazo de caña: Revisión}

RESUMEN. Uno de los grandes desafíos de la producción animal en Brasil es buscar alternativas alimentarias disponibles de acuerdo con las características regionales, eficientes, de bajo costo, que atiendan las necesidades de los animales y sean ambientalmente correctas. En este sentido, es importante que se evalúe la calidad de residuos de cultivos y residuos agroindustriales que presenten potencial para uso en la alimentación de rumiantes, y que también puedan estar disponibles en el período de escasez de alimentos, donde es necesaria la suplementación animal para la viabilidad de los sistemas productivos. Se pretende en esta revisión recopilar información para la formulación de un ensilaje a base de la palma forrajera consorciada con los residuos de la mandioca y bagazo de la caña de azúcar, de alto valor nutritivo y que no cause problemas digestivos para los animales. Se estudiarán $\mathrm{pH}$, materia seca (MS), materia mineral (MM), proteína bruta $(\mathrm{PB})$, extracto etéreo (EE), fibra en detergente neutro (FDN), fibra en detergente ácido (FDA), análisis sensorial del ensilaje y de pérdidas gaseosas. A partir del presente estudio, se pretende generar y disponibilizar informaciones y alternativas referentes a forrajes conservados en forma de ensilaje y, consecuentemente, contribuir al incremento de la rentabilidad de diversos segmentos de la cadena productiva de bovinos y ovinos en pastoreo.

Palabras clave: composición químico-bromatológica, conservación de forrajes

\section{Introdução}

A necessidade de produção e conservação de alimentos vem se acentuando com o aumento populacional dos seres vivos. Quando se trata da criação de animais como os ruminantes, a alimentação deve ser a primeira preocupação do produtor, devendo-o, considerar os períodos de entressafras ou sazonalidades como fatores de grande interferência na cadeia produtiva (Fontaneli et al., 2009; Prado, 2010). Neste contexto, a silagem se apresenta como uma excelente alternativa para alimentação dos animais (Brondani et al., 2000; Santos \& Zanine, 2007). A silagem é um alimento volumoso, obtido por um processo simples, pela fermentação de uma ou mais forrageiras de alto valor nutricional (Pedroso et al., 2008).

No Brasil, a produção de forrageiras acompanha as diversidades edafoclimáticas de cada região, tendo a palma forrageira (Nopalea cochenilifera), destaque na região nordeste, devido, a alta concentração de energia e água, minerais, boa digestibilidade, excelente palatabilidade, alta produtividade e disponibilidade nos períodos mais críticos de escassez de alimento (Lima et al., 2011; Marques et al., 2017).

Na região do Baixo Acre, o fácil acesso, possibilita à alguns agricultores, o uso, do terço médio da parte aérea da planta de mandioca, com consideráveis teores de proteína e o bagaço da cana de açúcar com alta concentração de fibra para alimentar seus animais. No caso de uma consorciação destes produtos com a palma forrageira, obter-se-á uma silagem adequada a alimentação de ruminantes. Um dos problemas da silagem a base da palma se fornecida como única fonte de alimento, são os baixos teores de fibra e proteína que causam problemas intestinais nos animais (Galvão Júnior et al., 2014; Marques et al., 2017).

Objetiva-se nesta revisão compilar informações para a formulação de uma silagem a base da palma forrageira consorciada com os resíduos da mandioca e bagaço da cana de açúcar, de alto valor nutritivo e que não cause problemas digestivos para os animais.

\section{Silagem}

Segundo Fontaneli et al. (2009), a silagem é definida como uma forragem úmida obtida pelo processo de conversão de açúcares em ácidos orgânicos pela fermentação anaeróbica da planta inteira ou de partes da mesma, com alto teor de umidade. $\mathrm{O}$ uso da silagem na alimentação dos ruminantes é eficiente, principalmente nos períodos onde há baixa produção de forragens, de acordo com sua composição, as silagens podem serem fontes de carboidratos, fibras, açúcares, proteínas e minerais (Bolsen et al., 1996; Fontaneli et al., 2009; Jahanzad et al., 2016).

Nos períodos de entressafras e nos locais que as condições climáticas promovem a escassez de alimentos, a silagem atua como importante componente na alimentação de animais, além do mais, ajuda o produtor a maximizar o uso da terra, 
utilizar melhor as horas de trabalho e ter o melhor controle da produção (Lima et al., 2011; Marques et al., 2017).

\section{Espécie palma forrageira (Nopalea cochenilifera L. Salm Dyck)}

A palma forrageira (Nopalea cochenilífera), variedade Miúda, pertence à família Cactaceae. Esta planta é originária do México. No século XX foi introduzida no Brasil pelos portugueses com intuito de ser utilizada como hospedeira do inseto Cochonilha do Carmim (Dactylopius coccus) para a produção de corante para tecidos (Chiacchio, 2008). É uma cactácea xerófila, de crescimento do tipo arbóreo de 3-5 $\mathrm{m}$ de altura, perene, rústica e resistente a seca. Contudo, a planta tem ampla capacidade de adaptação à diferentes condições edafoclimáticas, com uma variação de temperatura entre os limites $31,5^{\circ} \mathrm{C}$ máximo e $8,6^{\circ} \mathrm{C}$ mínimo e índices de precipitação de 400 a $800 \mathrm{~mm}$ anual (Santos et al., 1997). É uma cultura exigente quanto às características do solo, que deve apresentar boa fertilidade, textura arenosa à argilosa, drenagem eficiente, uma vez que solos encharcados dificultam o desenvolvimento da palma, e pH próximo de 7,0 (Barros et al., 2016; Galvão Júnior et al., 2014; Oliveira et al., 2011).

A propagação é por via sexuada ou assexuada. Sendo a propagação vegetativa por cladódio (modificação de caule e folhas) a mais utilizada (Teles et al., 2002). Em sistemas de plantios adensados é necessário realizar a adubação química, incluindo macro e micronutrientes, sendo a adubação nitrogenada a que mais influência o crescimento e produtividade da forrageira (Cândido et al., 2013). A colheita é realizada manualmente quando os palmais atingem idade entre 1 a 2 anos, seguindo-se cortes de intervalos anuais (Padilha Junior et al., 2016).

A palma forrageira realiza o processo fotossintético CAM (Metabolismo do Ácido das Crassuláceas), o que a torna muito eficiente no uso da água, armazenamento e absorção do $\mathrm{CO}_{2}$ (Gás Carbônico) no período noturno e transformação em biomassa durante o dia, indicada para as regiões onde a escassez de água é um fator limitante para a produção agropecuária (Oliveira et al., 2011; Santos et al., 1997).

Quando desidratada, a forrageira constitui excelente concentrado energético, suprindo a exigência de energia dos rebanhos durante a seca, mantendo-os em boa condição corporal, podendo inclusive propiciar ganhos razoáveis, desde que seja fornecida dentro de uma dieta que equacione seu baixo teor de proteína e de carboidratos fibrosos (Cândido et al., 2013).

A composição química da palma forrageira, varia com a espécie, idade da planta, época do ano, nível de fertilidade do solo e espaçamentos. No geral a planta é rica em carboidratos não fibrosos $(61,8 \%)$ e nutrientes digestíveis totais $(62,0 \%)$, teores consideráveis de matéria mineral $(12,0 \%)$ e independente do gênero, apresenta baixos teores de matéria seca $(11,7 \%)$, proteína bruta $(4,8 \%)$, fibra em detergente neutro - FDN (26,87\%), fibra em detergente ácido - FDA $(18,9 \%)$ (Valadares Filho, 2006).

Segundo Ferreira et al. (2009), a palma forrageira apresenta alta palatabilidade e grandes quantidades carboidratos não fibrosos, podendo ser voluntariamente consumidas pelos animais. No entanto, embora seja uma excelente fonte de energia, a planta apresenta baixos teores de matéria seca, fibras e proteína.

A forrageira pode substituir o milho, dado o seu alto valor energético e boa palatabilidade pelos animais. Pode ser fornecida como alimento em sistema de pastejo ou fatiada, fresca no comedouro, na forma de silagem, como componente de dieta completa com feno, restolho de sorgo, de milho, de feijão ou mesmo capim seco (Marques et al., 2017; Oliveira et al., 2011).

No entanto, para a palma apresentar grandes resultados é recomendado associá-la com uma fonte proteica, para satisfazer as exigências na dieta dos ruminantes, tendo em vista, que o indicado para este grupo de animais é de $6 \%$ a $7 \%$ de proteína bruta. Adequações dos teores de proteína, bem como o equilíbrio nutricional de modo geral, têm surtido efeito com associações a outros componentes na dieta como a cama de frango, a silagem de sorgo e o farelo de soja (Albuquerque et al., 2002; Geron et al., 2011).

\section{A cultura da mandioca (Manihot esculenta Crantz)}

A mandioca (Manihot esculenta Crantz) constitui uma das principais fontes de alimentos e energia para mais de 600 milhões de pessoas no mundo, especialmente, nas regiões tropicais em desenvolvimento (Iyer et al., 2010). A mandioca pertence à família Euphorbiaceae, de alta variabilidade genética (um pouco mais de quatro mil variedades), apesar de que, somente 98 espécies são reconhecidas nos bancos brasileiros de germoplasma de mandioca. Originária da 
América do Sul, onde o Brasil se apresenta como o maior detentor de diversidade do gênero Manihot. Caracterizada como uma planta alógama, subarbustiva, com caule ereto, lenhoso, com presença de nós, de crescimento continuo, propagação sexuada e assexuada. Sendo a última, a mais utilizada pelos produtores devido ao fácil acesso do material propagativo (Conceição, 1987).

A precipitação média anual exigida pela cultura varia de 1.000 a 1.500 milímetros. A luminosidade ideal, ou seja, o fotoperíodo ideal é de 12 horas de luz durante o dia, período maior ou menor do que este, prejudica tanto o desenvolvimento da parte aérea quanto o desenvolvimento das raízes (Conceição, 1987).

De acordo com o mesmo autor, para cultivo de mandioca, o solo ideal é o que facilita a colheita, deve apresentar boa drenagem, textura que pode variar de franco-arenosa a argilo arenosa. Tolera solos ácidos, mas não suporta solos alcalinos, e o pH deve ficar entre 5,5 e 6,5.

A colheita da mandioca pode ser realizada a partir da maturidade das raízes, variando entre variedades, que vão de 6 até 24 meses após plantio. A oferta aos animais, é dependente dos fatores de cultivo, possibilitando ao produtor, escalonar a época de colheita de acordo com o período de maior necessidade de reserva de alimento na propriedade, não sendo necessário grandes investimentos em infraestrutura de armazenamento (Albuquerque et al., 2009).

A raiz da mandioca apresenta em torno de 60,0 a $65,0 \%$ de umidade; 21,0 a $33,0 \%$ de amido; 1,0 a $1,5 \%$ de proteína bruta; 0,18 a $0,24 \%$ de extrato etéreo; 0,70 a $1,06 \%$ de fibra bruta e 0,60 a $0,90 \%$ de matéria mineral (Valadares Filho, 2006).

A parte aérea é de extrema importância na mandiocultura, tanto como material de propagação vegetativa, como para a produção de forragem para a alimentação animal (Vidigal Filho et al., 2000). A composição bromatológica da parte aérea é muito variável. Os níveis de proteína bruta variam de $8 \%$, quando se usa bastante maniva, e $28-32 \%$ quando se utiliza apenas o limbo foliar. A parte aérea pode ser processada fornecendo diferentes frações de composições diferenciadas (Butolo, 2002). Suas folhas são ricas em vários nutrientes, principalmente em proteínas, chegando a possuir até $28 \%$ de proteína bruta, com alto teor de vitaminas, especialmente A, C e do complexo B; conteúdo de minerais relativamente alto, especialmente cálcio e ferro (Montaldo et al., 1994; Valadares Filho, 2006).

$\mathrm{Na}$ alimentação animal, a parte aérea pode ser considerada um volumoso relativamente rico em proteínas e com níveis apreciáveis de carboidratos não estruturais, podendo ser utilizada na forma fresca, ensilada ou na forma de feno, com composições variáveis em função da proporção de caules e folhas e da altura de colheita do material (Marques et al., 2000), características que comprovam, sua qualidade como alternativa aos produtores de leite e de gado de corte nas regiões em que a mandioca é cultivada, diminuindo, assim, os custos da produção.

\section{A cultura da cana de açúcar (Saccharum officinarum)}

A cana de açúcar (Saccharum officinarum) é uma planta da família das gramíneas, originária da Ásia Meridional, bastante cultivada em países tropicais e subtropicais (Borges et al., 2008). Atualmente, o Brasil se destaca no cenário mundial como o maior produtor de cana-deaçúcar. Contudo, a planta não é importante somente para o setor industrial do açúcar e do álcool, mas também como fonte de volumoso suplementar aos animais (Queiroz et al., 2008).

É uma planta herbáceas, perene, possui nós e entrenós, epiderme característica, raiz fasciculada e flores monoclinas (Borges et al., 2008).

Em termos de exigência climática a cana apresenta particularidades, na fase de brotação, perfilhamento e crescimento vegetativo, primeira fase do ciclo da cultura, exige temperatura média de $20^{\circ} \mathrm{C}$, sendo a faixa ideal de $25^{\circ} \mathrm{C}$ a $30^{\circ} \mathrm{C}$, e umidade disponível no solo. Já na fase de maturação, segunda fase do ciclo da cultura, a cana exige temperaturas em torno de $20^{\circ} \mathrm{C}$ e/ou déficit hídrico, para que entre em repouso fisiológico e haja um maior acúmulo de sacarose nos colmos (Lopes \& Evangelista, 2010). O clima ideal é aquele que apresenta duas estações distintas, quente e úmida, para proporcionar a germinação, perfilhamento e desenvolvimento vegetativo, e outra fria e seca, para promover a maturação e por consequência o acumulo de sacarose nos colmos (Ferro et al., 2017; Maeda et al., 2011).

A falta de chuva provoca a morte da planta, o ideal é que durante a fase de crescimento, a 
umidade esteja entre 80 e $85 \%$, fator que favorece o alongamento rápido da cana e durante o amadurecimento, a umidade fique entre 45 e $65 \%$, favorecendo o acúmulo de açúcar na cana (Ávila et al., 2008; Rezende et al., 2009). O plantio da cana de açúcar é realizado em duas épocas, dando origem à cana-planta de ano ou à cana-planta de ano e meio, mas após o primeiro corte, o ciclo de ambas é anual e ela recebe a denominação de canasoca (Barbosa et al., 2014).

A colheita do canavial é realizada anualmente e de forma manual, sendo que o aumento do número dos estágios de corte ocasiona uma perda gradativa de produtividade. Quando a lavoura não for viável economicamente com relação aos custos da colheita e o rendimento do canavial, a área é reformada com o plantio de novas mudas (Sugawara \& Rudorff, 2011). A cultura da cana de açúcar, apresenta grande eficiência quanto a sua suplementação volumosa, sendo assim, é uma alternativa para os produtores como alimentação de ruminantes nos períodos de estiagens prolongadas, contando que nesta época, acontece a menor produção de pastagens (Borges et al., 2008). A cana de açúcar quando colhida no estádio correto de maturidade apresenta alto teor de matéria seca adequado à ensilagem (29 a 33\% de MS) e bastante presença de carboidratos solúveis, como é o caso da sacarose, o que permitem o rápido crescimento microbiano e redução do $\mathrm{pH}$, com valores inferiores a 4,0 após três dias de fermentação (Pedroso et al., 2005). Contudo, o alto teor de sacarose e a grande população epifítica de leveduras na cana de açúcar (Ávila et al., 2010), acarreta uma intensa fermentação etanoica nas silagens dessa forragem, resultando em elevadas perdas de matéria seca, alto teor de etanol nas silagens e prejuízo no desempenho dos animais (Pedroso et al., 2006; Schmidt et al., 2014).

A alta produção de matéria seca por área, facilidade na condução da cultura, aceitação dos animais, aliados à redução dos custos com a suplementação na época seca, estimulam o uso da cana de açúcar como forragem (Bonomo et al., 2009).

O bagaço de cana constitui uma fonte alimentar promissora para ruminantes, uma vez, que o período de safra da cana coincide com o período de escassez de alimentos volumosos em várias regiões do Brasil. Apesar do potencial para suprir parte das exigências dos animais, sobretudo no período da seca, normalmente, o valor nutritivo do bagaço de cana é baixo, pois esse alimento possui baixo teor de proteína e minerais e elevado teor de fibra (Prado \& Moreira, 2002). O bagaço da cana de açúcar, resultado da extração do caldo após esmagamento nas moendas, é o maior resíduo da agroindústria brasileira.

Segundo Souza et al. (2015), de cada tonelada de cana moída na indústria obtêm-se 700 litros de caldo de cana e $300 \mathrm{~kg}$ de bagaço (50\% MS), portanto, das 250 milhões de toneladas de cana moída nas usinas e destilarias do Brasil, a cada ano, 75 milhões de toneladas de bagaço de cana são obtidos.

O principal problema do bagaço de cana, que limita seu uso na alimentação animal, é o alto teor de fibra (de baixo valor energético) que dificulta a digestão dos animais (Carvalho et al., 2005).

\section{Considerações finais}

A escassez de alimentos é um problema recorrente em todas as regiões brasileiras, durante os períodos de seca, forçando os agricultores buscarem fontes alternativas de alimentos, onde a silagem apresenta-se como solução viável, permitindo que os animais atravessem este período com bom escore corporal, reduzindo os impactos negativos na produção.

A silagem a base da palma forrageira com os resíduos da mandioca e da cana de açúcar é uma alternativa alimentar viável para a produção de animais.

\section{Referências}

Albuquerque, J. A. A., Sediyama, T., Silva, A. A., Sediyama, C. S., Alves, J., \& Assis Neto, F. 2009. Caracterização morfológica e agronômica de clones de mandioca cultivados no Estado de Roraima. Revista Brasileira de Ciências Agrárias, 4(4), 388-394.

Albuquerque, S. S. C., Lira, M. A., Santos, M. d., Dubeux Jr, J. C. B., Melo, J. N., Santos, D. C., \& Farias, I. 2002. Utilização de três fontes de nitrogênio associadas à palma forrageira (Opuntia ficusindica, Mill.) cv. Gigante na suplementação de vacas leiteiras mantidas em pasto diferido. Revista Brasileira de Zootecnia, 31(3), 1315-1324.

Ávila, C. L. S., Bravo, M. C. E. C., \& Schwan, R. F. 2010. Identification and characterization of yeasts in sugarcane silages. Journal of Applied Microbiology, 109, 1677-1686.

Ávila, C. L. S., Pinto, J. C., Sugawara, M. S., Silva, M. S., \& Schwan, R. F. 2008. Qualidade 
da silagem de cana-de-açúcar inoculada com uma cepa de Lactobacillus buchneri. Acta Scientiarum. Animal Sciences, 30(3), 255-261.

Barbosa, F. S., Coelho, R. D., Lima, C. J. G. S., Maschio, R., \& Silva, E. M. 2014. Resistência à seca em cana-de-açúcar para diferentes níveis de disponibilidade hídrica no solo. Engenharia Agrícola, 34(2), 203-210.

Barros, J. L., Donato, S. L. R., Gomes, V. M., Donato, P. E. R., Silva, J. A., \& Padilha Júnior, M. C. 2016. Palma forrageira 'Gigante' cultivada com adubação orgânica. Revista Agrotecnologia, 7(1), 53-65.

Bolsen, K. K., Ashbell, G., \& Weinberg, Z. G. 1996. Silage fermentation and silage additivesReview. Asian-Australasian Journal of Animal Sciences, 9(5), 483-494. doi: https://doi.org/10.5713/ajas.1996.483

Bonomo, P., Cardoso, C. M. M., Pedreira, M. S., Santos, C. C., Pires, A. J. V., \& Silva, F. F. 2009. Potencial forrageiro de variedades de cana-de-açúcar para alimentação de ruminantes. Acta Scientiarum. Animal Sciences, 31(1), 54-59.

Borges, A. L. C. C., Campos, M. M., \& Reis, S. R. 2008. Cana-de-açúcar na alimentação de bovinos. Revista Veterinária e Zootecnia em Minas, 1/2/3(96), 1-4.

Brondani, I. L., Alves Filho, D. C., Bernardes, R. A. C., \& Restle, J. 2000. Silagem de alta qualidade para bovinos. In j. Restle (Ed.), Eficiência na produção de bovinos de corte. Santa Maria: Universidade Federal de Santa Maria (Vol. 1, pp. 185-204. Santa Maria, Rio Grande do Sul: Universidade Federal de Santa Maria.

Butolo, J. E. 2002. Qualidade de ingredientes na alimentação animal. Campinas: Butolo.

Cândido, M. J. D., Gomes, G. M. F., Lopes, M. N., \& Ximenes, L. J. F. 2013. Cultivo da palma forrageira para mitigar a escassez de forragem em regiões semiáridas. Informe Rural, 7(3), 17.

Carvalho, M. C., Ferreira, M. A., Cavalcanti, C. V. A., Lima, L. E., Silva, F. M., Miranda, K. F., . . . Feitosa Vieira, V. C. 2005. Associação do bagaço de cana-de-açúcar, palma forrageira e uréia com diferentes suplementos em dietas para novilhas da raça holandesa. Acta Scientiarum. Animal Sciences, 27(2), 247-252.
Chiacchio, F. P. B. 2008. Incidência da cochonilha do carmim em palma forrageira. Bahia Agrícola, 8(2), 12-14.

Conceição, A. J. (1987. A mandioca.

Ferreira, M. A., Silva, F. M., \& Bispo, S. V. 2009. Estratégias na suplementação de vacas leiteiras no semi-árido do Brasil. Revista Brasileira de Zootecnia, 38, 322-329.

Ferro, M. M., Castro, W. J. R., Zanine, A. M., \& Souza, A. L. 2017. Cinética de fermentação ruminal in vitro de silagem de cana-de-açúcar com resíduo de cervejaria desidratado. Archivos de Zootecnia, 66(254), 237-242.

Fontaneli, R. S., Santos, H. P., \& Fontaneli, R. S. 2009. Forrageiras para integração lavourapecuária-floresta na região sul-brasileira (Vol. 1). Passo Fundo, Rio Grande do Sul: Embrapa.

Galvão Júnior, J. G. B., Silva, J. B. A., Morais, J. H. G., \& Lima, R. N. 2014. Palma forrageira na alimentação de ruminantes: cultivo e utilização. Acta Veterinaria Brasilica, 8(2), 78-85.

Geron, L. J. V., Zeoula, L. M., Paula, E. J. H., Ruppin, R. F., Rodrigues, D. N., \& Moura, D. C. 2011. Inclusão do caroço de algodão em rações de alto concentrado constituído de coprodutos agroindustriais sobre o desempenho animal em tourinhos confinados. Archives of Veterinary Science, 16(3), 14-24.

Iyer, S., Mattinson, D. S., \& Fellman, J. K. 2010. Study of the early events leading to cassava root postharvest deterioration. Tropical Plant Biology, 3(3), 151-165.

Jahanzad, E., Sadeghpour, A., Hashemi, M., Keshavarz Afshar, R., Hosseini, M. B., \& Barker, A. V. 2016. Silage fermentation profile, chemical composition and economic evaluation of millet and soya bean grown in monocultures and as intercrops. Grass and Forage Science, 71(4), 584-594.

Lima, M. S., Silva, D. M. P., Falcão, H. M., Ferreira, W. M., Silva, L. D., \& Paranhos, B. A. J. 2011. Predadores associados à Dactylopius opuntiae (Hemiptera: Dactylopiidae) em palma forrageira no estado de Pernambuco, Brasil. Revista Chilena de Entomologia, 36, 51-54.

Lopes, J., \& Evangelista, A. R. 2010. Características bromatológicas, fermentativas e população de leveduras de silagens de canade-açúcar acrescidas de ureia e aditivos 
absorventes de umidade. Revista Brasileira de Zootecnia, 39(5), 984-991.

Maeda, E. M., Zeoula, L. M., Jobim, C. C., Bertaglia, F., Jonker, R. C., Geron, L. J. V., \& Henrique, D. S. 2011. Chemical composition, fermentation, in vitro digestibility and in situ degradability of sugar cane silages with Lactobacillus, urea and agricultural byproduct. Revista Brasileira de Zootecnia, 40(12), 28662877.

Marques, J. A., Prado, I. N., Zeoula, L. M., Alcalde, C. R., \& Nascimento, W. G. 2000. Avaliação da mandioca e seus resíduos industriais em substituição ao milho no desempenho de novilhas confinadas. Revista Brasileira de Zootecnia, 29(5), 1528-1536.

Marques, O. F. C., Paula Gomes, L. S., Mourthé, M. H. F., Santos, T. G. B., \& Pires Neto, O. S. 2017. Palma forrageira: cultivo e utilização na alimentação de bovinos. Caderno de Ciências Agrárias, 9(1), 75-93.

Montaldo, A., Moontilla, J. J., \& Escobar, J. (1994. El follage de yuca como fuente potencial de proteínas. Revista Brasileira de Mandioca, 1, 123-136.

Oliveira, S. C., Cavalcante Filho, F. N., Rangel, A. H. N., \& Lopes, K. B. P. 2011. A palma forrageira: alternativa para o semi-árido. Revista Verde de Agroecologia e Desenvolvimento Sustentável, 6(3), 49-58.

Padilha Junior, M. C., Donato, S. L. R., Silva, J. A., Donato, P. E. R., \& Souza, E. S. 2016. Características morfométricas e rendimento da palma forrageira 'Gigante'sob diferentes adubações e configurações de plantio. Revista Verde de Agroecologia e Desenvolvimento Sustentável, 11(1), 67-72.

Pedroso, A. d. F., Nussio, L. G., Barioni Júnior, W., Rodrigues, A. d. A., Loures, D. R. S., Campos, F., Junqueira, M. 2006. Performance of Holstein heifers fed sugarcane silages treated with urea, sodium benzoate or Lactobacillus buchneri. Pesquisa Agropecuária Brasileira, 41(4), 649-654.

Pedroso, A. F., Nussio, L. G., Loures, D. R. S., Paziani, S. F., Ribeiro, J. L., Mari, L. J., Horii, J. 2008. Fermentation, losses, and aerobic stability of sugarcane silages treated with chemical or bacterial additives. Scientia Agricola, 65(6), 589-594.

Pedroso, A. F., Nussio, L. G., Paziani, S. F., Loures, D. R. S., Igarasi, M. S., Coelho, R. M., . . . Gomes, L. H. 2005. Fermentation and epiphytic microflora dynamics in sugar cane silage. Scientia Agricola, 62(5), 427-432.

Prado, I. N. 2010. Produção de bovinos de corte e qualidade da carne (Vol. 1). Maringá, Paraná, Brasil: Eduem.

Prado, I. N., \& Moreira, F. B. 2002. Suplementação de bovinos no pasto $e$ alimentos usados na bovinocultura (Vol. 1). Maringá, Paraná, Brasil: Eduem.

Queiroz, O. C. M., Nussio, L. G., Schmidt, P., Ribeiro, J. L., Santos, M. C., \& Zopollatto, M. 2008. Silagem de cana-de-açúcar comparada a fontes tradicionais de volumosos suplementares no desempenho de vacas de alta produção. Revista Brasileira de Zootecnia, 37(2), 358-365.

Rezende, A. V., Rodrigues, R., Barcelos, A. F., Casali, A. O., Valeriano, A. R., \& Medeiros, L. T. 2009. Qualidade bromatológica das silagens de cana-de-açúcar (Saccharum officinarum L.) aditivadas com raspa de batata. Ciência $e$ Agrotecnologia, 33(1), 292-297.

Santos, D., Farias, I., Lira, M., Tavares Filho, J., Santos, M., \& Arruda, G. 1997. A palma forrageira (Opuntia ficus-indica Mill $e$ Nopalea cochenillifera Salm-Dyck) em Pernambuco: cultivo e utilização. Recife: IPA.

Santos, E. M., \& Zanine, A. M. 2007. Silagem de gramíneas tropicais. Colloquium Agrariae, 2(1), 32-45.

Schmidt, P., Nussio, L. G., Queiroz, O. C. M., Santos, M. C., Zopollatto, M., Toledo Filho, S. G. d., \& Daniel, J. L. P. 2014. Effects of Lactobacillus buchneri on the nutritive value of sugarcane silage for finishing beef bulls. Revista Brasileira de Zootecnia, 43(1), 8-13.

Souza, A. C., Fugita, F. I., Sousa, A. H., \& Santos, B. D. C. 2015. Estudo das aplicações do bagaço da cana-de-açúcar dentro e fora das indústrias sucroalcooleiras. Revista Brasileira de Energia, 21, 91-115.

Sugawara, L. M., \& Rudorff, B. F. T. 2011. Acompanhamento do crescimento vegetativo da cana-de-açúcar por meio de séries temporais de NDVI do sensor MODIS. Paper presented at the Simpósio Brasileiro de Sensoriamento Remoto, Curitiba, Paraná, Brasil.

Teles, M. M., Santos, M. V. F., Dubeux Júnior, J. C. B., Bezerra Neto, E., Ferreira, R. L. C., Lucena, J. E. C., \& Lira, M. A. 2002. Efeitos da adubação e de nematicida no crescimento e 
na produção da palma forrageira (Opuntia ficus indica Mill) cv. Gigante. Revista Brasileira de Zootecnia, 31(1), 52-60.

Valadares Filho, S. C. 2006. Tabelas brasileiras de composição de alimentos para bovinos (Vol. 1). Viçosa: UFV.

Vidigal Filho, P. S., Pequeno, M. G., Scapim, C. A., Vidigal, M. C. G., Maia, R. R., Sagrilo, E., Lima, R. S. 2000. Avaliação de cultivares de mandioca na região noroeste do Paraná. Bragantia, 59(1), 69-75.

Recebido: 20 Agosto 2018.

Aprovado:22 Setembro 2018.

Publicado: 30 Novembro 2018.

Licenciamento: Este artigo é publicado na modalidade Acesso Aberto sob a licença Creative Commons Atribuição 4.0 (CC-BY 4.0), a qual permite uso irrestrito, distribuição, reprodução em qualquer meio, desde que o autor e a fonte sejam devidamente creditados. 